\title{
We Play - Um aplicativo educativo para resgatar brincadeiras da infância
}

\author{
Débora Nasser Diniz, Deborah Barros F. Puperi, Luiz Gustavo X. Janeiro, Elton José da Silva \\ ${ }^{1}$ Departamento de Ciência da Computação - Universidade Federal De Ouro Preto (UFOP) \\ CEP 35400-000 - Ouro Preto - MG - Brasil \\ \{debnasser_26, deborahpuperi, luizjaneiro007\}@hotmail.com, elton@decom.ufop.br
}

\begin{abstract}
Resumo. Pensava-se que o acesso das crianças às tecnologias seria um incentivo a multiplicar informações e o círculo de amizade, porém, muitas crianças nunca estiveram tão isoladas. Com isso, surgem problemas como a falta de interação social, baixo rendimento escolar, ou até mesmo o perigo das redes sociais. Um grande desafio enfrentado pelos pais é o monitoramento das crianças quanto ao acesso e uma alternativa para isso seria através da utilização de um aplicativo que motivasse as crianças a utilizar o celular de forma educativa. Motivados por isso, este trabalho propõe o desenvolvimento de um aplicativo Android, utilizando a abordagem Design Thinking, denominado We Play que sugere e ensina brincadeiras que caíram em desuso às crianças.
\end{abstract}

\section{Cenário de uso}

É perceptível que ao longo dos últimos anos as crianças vêm tendo acesso às tecnologias cada vez mais cedo e o aumento da dependência de eletrônicos tem preocupado pais e educadores.

O uso excessivo de eletrônicos pode acarretar tanto em problemas físicos (tendinites, obesidade, dores cervicais), como em mentais e emocionais (isolamento social, dificuldade de concentração). Porém, o uso de dispositivos tecnológicos por crianças e jovens está longe de ser prejudicial se for bem orientado e pode estimular criatividade, raciocínio lógico, colaboração, capacidade de pesquisa, entre outras competências valiosas.

Com o intuito de aproveitar esse uso da tecnologia por crianças para tentar afastálas um pouco dos dispositivos eletrônicos e estimular o contato social e aprendizagem, foi proposta uma aplicação para Android que busca reviver brincadeiras que caíram em desuso, como rouba bandeira e queimada. A aplicação tem a ideia de conectar crianças, com supervisão dos pais, para que elas possam brincar e usar menos tecnologia.

Com o passar do tempo, os jogos e as brincadeiras deixaram de ser apenas atividades lúdicas para serem também atividades educativas. Dessa forma, o We Play pode ser utilizando tanto por crianças, quanto por educadores, como em uma aula de Educação Física. Esta disciplina escolar tem a finalidade semelhante ao aplicativo, que é mostrar às crianças novas formas de brincar exercitando sua criatividade.

Em [Elkonin 1998] o autor menciona que os jogos de papéis coletivos, que são um tipo de jogo de faz-de-conta, beneficiam o desenvolvimento cognitivo. Esses jogos favorecem a aprendizagem cooperativa, ou seja, favorece a capacidade da criança de descentrar de si mesma. Uma criança coordena suas ações nos seus papéis e contra-papéis ao brincar com outras. Desta forma, o jogo coletivo propicia que ela atue sobre os objetos de 
acordo com determinados significados, mas que ordene seus pontos de vista em relação a tais significados.

Em [dos Santos 2000] o autor reforça que educadores, psicólogos e pais, devem reconhecer a importância dos jogos e brincadeiras no contexto escolar, e também estudálas para saber como usar essas brincadeiras de forma adequada. Além disso, [Pinto 2003] diz que as brincadeiras proporcionam boa saúde física e mental para as crianças. A brincadeira, desde que aplicada de forma correta proporciona diversos objetivos, como: socializar, divertir, ensinar, aprender, se unir, transmitir conhecimento, entre outros.

Contudo, o jogo é um processo lúdico e criativo que obedece à regras e que possibilita às crianças imaginar um mundo diferente da realidade, pois funciona como elo integrador entre os três domínios do conhecimento o psicomotor, cognitivo e o afetivosocial.

\section{Design Thinking}

Design Thinking é uma abordagem centrada no usuário e busca soluções de forma coletiva e com compreensão máxima dos seus stakeholders durante todo o desenvolvimento do produto. É uma ferramenta útil que aplica o pensamento criativo e crítico para compreender, visualizar e descrever problemas e, em seguida, desenvolver abordagens práticas para resolvê-los. [Brown et al. 2010]

O método é útil porque define uma visão real do mundo, com o interesse de compreender melhor os problemas,o que facilitaria o caminho para encontrar alternativas viáveis para corrigí-los. O motivo da escolha deste método é devido à busca pela satisfação do cliente, uma vez que o processo facilita o conhecimento das suas necessidades, desejos e percepções de mundo.

A seguir, será apresentado o Design Thinking e a sua aplicação no desenvolvimento do We Play.

\subsection{Empatia}

Este primeiro passo compreende um estudo sobre o ambiente em que se deseja inovar, procurando entender quais as necessidades das pessoas envolvidas.

Segundo [Cooper et al. 2007], personas fornecem uma forma precisa de pensar e comunicar sobre como os usuários se comportam, como eles pensam, o que desejam realizar, e por quê. Portanto, para auxiliar no desenvolvimento do software foram criadas duas personas: o Pedro e a Luiza, mostradas na Figura 1.
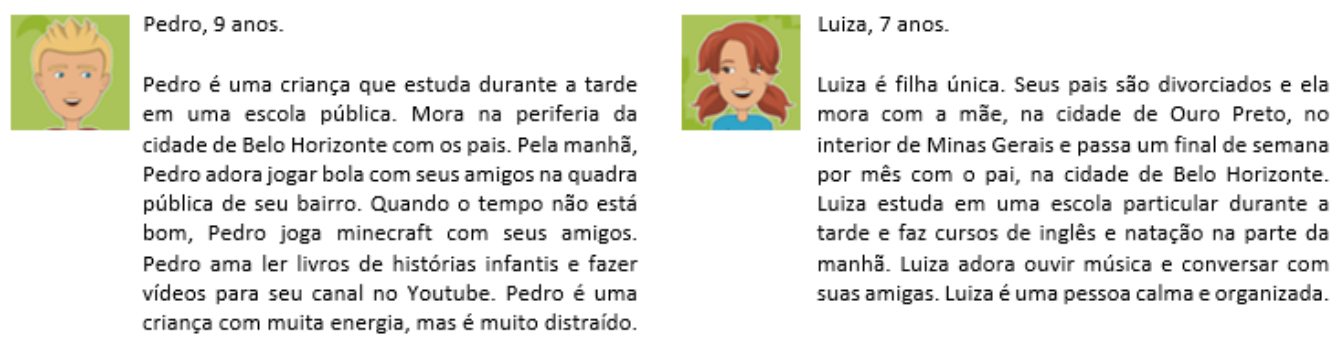

Figura 1. Personas do We Play 
VI Congresso Brasileiro de Informática na Educação (CBIE 2017)

Anais dos Workshops do VI Congresso Brasileiro de Informática na Educação (WCBIE 2017)

Foi criado um cenário (ver Figura 2), através de história em quadrinhos, para representar um possível caso de uso do nosso software pelas duas personas criadas.

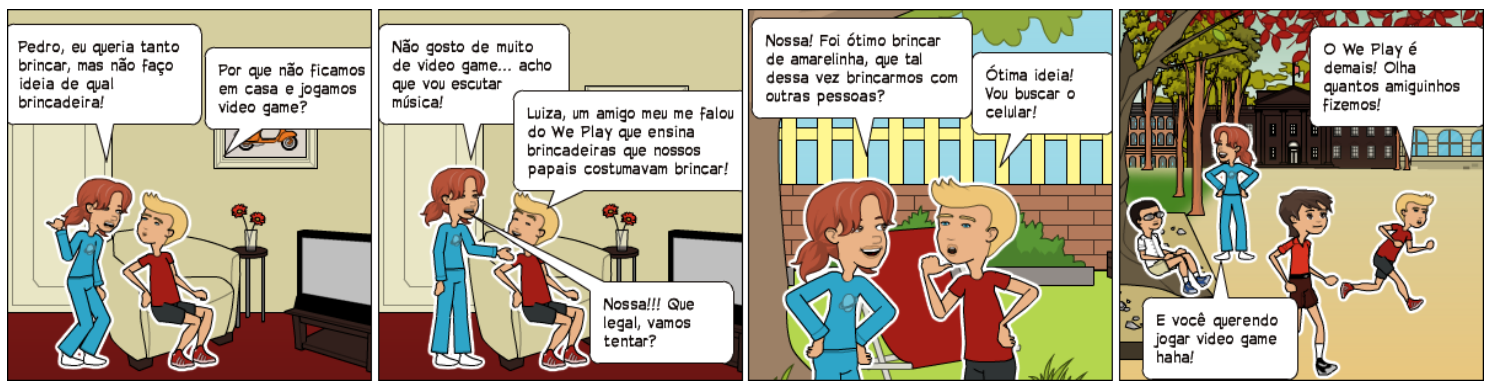

Figura 2. Cenário do We Play

\subsection{Definição}

Depois de entender problemas que o público-alvo possui, as informações obtidas na etapa 1 devem ser processadas e conectadas ao conhecimento que já se possuía. Nessa etapa geralmente é traçado um perfil consolidado do cliente.

O cliente típico do We Play são crianças que já sabem um mínimo de leitura e escrita. $\mathrm{O}$ alvo principal da aplicação, apesar de poder ser utilizada por todas as crianças, são aquelas que fazem uso excessivo da tecnologia e que abdicam de interações sociais por este motivo. Sendo assim, espera-se uma aplicação que seja fácil de usar, eficiente, e que atraia o tipo de público para o qual foi desenvolvida.

\subsection{Idealização}

Com o problema definido, então o passo seguinte é pensar em como abordá-lo. Para isto foram realizadas algumas sessões de brainstorming com o objetivo de préselecionar abordagens, mostrando como cada uma delas se distingue do senso comum. Após algumas discussões internas e validações, algumas soluções foram encontradas.

A primeira das soluções foi obtida pensando no fato de que as crianças podem ainda não ter muita intimidade com a leitura. Para isso, o We Play assumiu a caligrafia infantil ao ser escrito em letras maiúsculas e com estilo de fonte escrito a mão para facilitar a compreensão das crianças.

Outra solução foi a utilização do agente de interface Caco, o macaco, que simplifica e auxilia no uso da aplicação. Um macaco foi escolhido pela figura brincalhona e divertida que o animal representa.

Aproveitando a imagem do macaco com a intenção de se escolher um ícone de aplicativo (ver Figura 3) chamativo e que desperta a curiosidade do olhar, o agente, assumindo papel de mascote, ganhou destaque com cores quentes em um fundo azul, de cor fria. Além disso, para o ícone continuar transmitindo a personalidade do aplicativo, ele possui uma escolha de cores planejada.

Procurou-se uma paleta de cores (ver Figura 3) que representasse energia e confiança. Pelo estudo da psicologia das cores concluí-se que laranja é a cor que mais 
VI Congresso Brasileiro de Informática na Educação (CBIE 2017)

Anais dos Workshops do VI Congresso Brasileiro de Informática na Educação (WCBIE 2017)

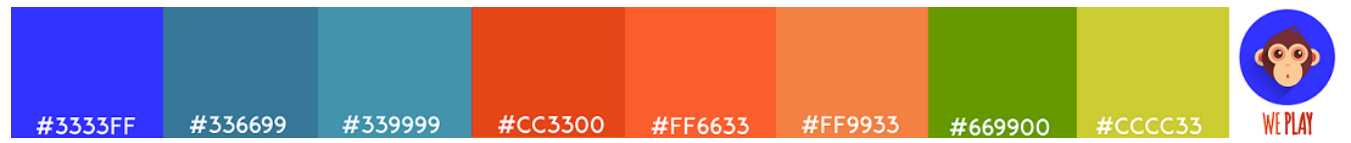

Figura 3. Paleta de cores

combina com o aplicativo, pois ela passa a ideia de alegria, entusiasmo, diversão, juventude e recreação. Sua cor oposta, azul, complementa as virtudes a serem transmitidas: segurança e confiança, valores essenciais para os pais. Trabalhar com um tom saturado e cores opostas resulta em uma paleta vibrante e altamente contrastante, sendo compatível com o público infantil. Van Gogh [Heller 2013] disse "não existe laranja sem azul", afirmando que ao combinar estas duas cores o significado psicológico transmitido pela cor laranja são reforçados. O verde foi escolhido para representar a natureza e as brincadeiras fora de casa, sendo uma cor análoga ao azul e finaliza a escolha de cores com coerência e harmonia entre elas.

\subsection{Prototipação}

Nesta etapa, as ideias e percepções saem do papel para a montagem de um produto simples. As coletas de feedbacks foram realizadas apenas junto à equipe e algumas versões do produto foram geradas até chegar à final.

Inicialmente, um protótipo simples foi criado utilizando apenas o Balsamiq Mockups (ver Figura 4 a). Com base nesse protótipo criou-se o projeto clicável para Android, utilizando o Android Studio, tentando atender todas as soluções propostas na etapa de idealização. Foram desenvolvidas duas versões: uma antes dos testes (ver Figura 4b) e uma após os testes realizados (ver Figura 4p).

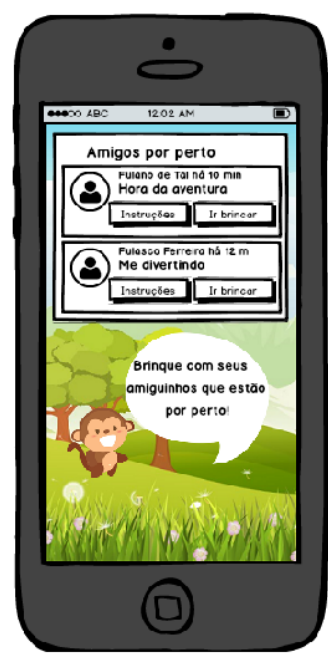

(a)

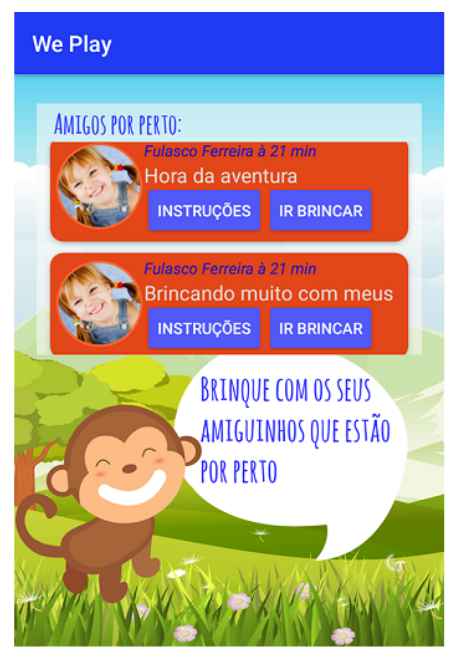

(b)

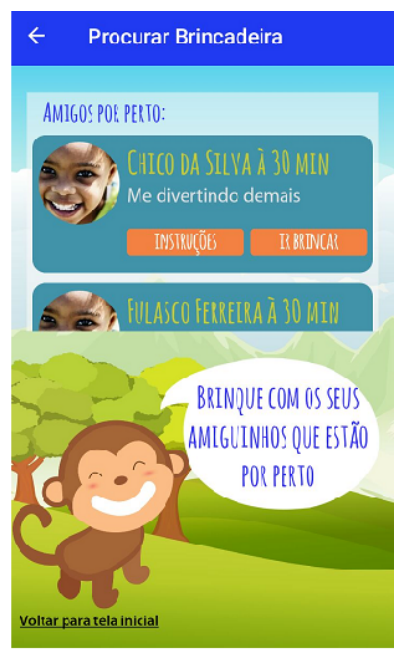

(c)

Figura 4. Protótipos: (a) versão Balsamiq Mockups; (b) versão Android antes dos testes; (c) versão Android depois dos testes 
VI Congresso Brasileiro de Informática na Educação (CBIE 2017)

Anais dos Workshops do VI Congresso Brasileiro de Informática na Educação (WCBIE 2017)

\subsection{Testes}

Após a prototipação, inicia-se a etapa de teste, que tem como objetivo o relato de possíveis problemas existentes nos protótipos. Esta etapa é importante porque reduz a probabilidade de ocorrência de erros quando o aplicativo for desenvolvido. Sendo assim, foram realizados dois tipos de testes: a inspeção semiótica e o teste com usuários.

\subsubsection{Inspeção semiótica}

O Método de Inspeção Semiótica realiza a avaliação da comunicabilidade de sistemas por meio da inspeção, simulando situações reais de uso com o objetivo de identificar rupturas de comunicação. Com isso, o objetivo desta avaliação é localizar falhas da comunicação do designer com o preposto do design.

Sendo assim, através da inspeção semiótica foi possível detectar alguns problemas, que foram corrigidos antes do teste com usuários. São eles:

- Em várias telas foram encontrados botões que poderiam ser confundidos com textos, uma vez que não existia uma caixa ao redor dos mesmo. Sendo assim, botões foram reprojetados para um melhor entendimento;

- Faltava uma interação com os amigos na timeline porque a única função da timeline era visualizar as fotos e vídeos dos amigos. Para isto, foi desenvolvido o botão de reação "gostei";

- Faltavam botões de voltar para a tela anterior visitada e para a timeline. A correção foi adicionar estes botões nas telas que foram necessárias;

- Não existia um feedback ao usuário indicando o sucesso do cadastro. Assim, incluiu-se uma mensagem de confirmação de cadastro para o usuário.

- Não era possível sair da conta que foi acessada. Para resolver, foi adicionada a opção "Sair"no menu.

\subsubsection{Teste com usuários}

Para os testes com usuários foram selecionadas três crianças (os nomes são fictícios): Jéssica - 7 anos, Fabiana - 6 anos e João - 7 anos. Um termo de consentimento contendo autorização para divulgação das imagens das crianças foi assinado pelo responsável das mesmas. Foi pedido aos usuários que criassem uma brincadeira no We Play, sendo que foi filmada a reação da criança e a tela do aplicativo durante a execução da atividade. Foram detectadas algumas observações em relação ao sistema:

- A tela inicial do aplicativo não possuía ajuda e os usuários tiveram dificuldades para localizar e identificar que o Caco é o agente que iria auxiliá-lo na criação do jogo. Para resolver, foi criado o tutorial do We Play;

- Notou-se a falta de uma tela que apresentasse o agente para o usuário. Durante toda a aplicação não foi citado o nome "Caco". Pensando nisso, foi incluída a apresentação do agente no tutorial.

- O botão de reação "gostei"não foi reconhecido pelos usuários. Sendo assim, mudou-se a estética do botão; 
VI Congresso Brasileiro de Informática na Educação (CBIE 2017)

Anais dos Workshops do VI Congresso Brasileiro de Informática na Educação (WCBIE 2017)

- A Fabiana (6 anos) não possui boa prática de leitura e encontrou dificuldades para desempenhar as tarefas. Sendo assim, constatou-se que o perfil dos usuários pensado (crianças que já sabem um mínimo de leitura e escrita) é o ideal. Porém, uma vez que a Flávia teve ajuda para ler os textos, ela conseguiu desempenhar corretamente a tarefa;

- As crianças se mostraram bem adeptas ao agente utilizado, o Caco. O Caco trouxe a proximidade esperada do sistema em relação às crianças;

- Fabiana e João tiveram dificuldades para entender qual o momento em que eles iriam brincar. Pensando nisso, foi desenvolvida a tela em que o Caco diz para as crianças irem brincar;

- Foi relatado pelos usuários o excesso de texto nas últimas telas da aplicação. Assim, o texto foi modificado a fim de facilitar a interação;

Além disso, as crianças disseram que utilizariam o aplicativo para indicar a brincadeira que iriam jogar com seus amigos. A Jéssica demonstrou grande animação ao contar para a mãe sobre a experiência de utilizar o protótipo.

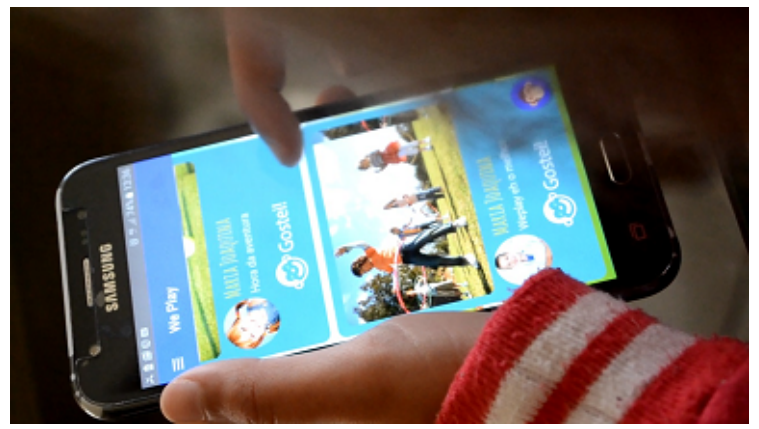

Figura 5. Teste com usuários

\section{Apresentação de software}

O We Play é uma aplicação social que envolve brincadeiras a fim de estimular a interação social e o aprendizado. Inicialmente, o usuário deve logar no sistema utilizando um e-mail e uma senha (ver Figura 6a). Caso o mesmo não possua um perfil, deve se cadastrar primeiro (ver Figura 6p). Para isso, deverá informar alguns dados, incluindo o e-mail de um responsável, para que o mesmo autorize a criança à utilizar o aplicativo.

Uma vez dentro do sistema, a timeline (ver Figura 66) é exibida contendo a fotos ou vídeos dos amigos do usuário. Ao clicar no ícone superior esquerdo (navigation drawer) o usuário tem acesso a várias informações como sua galeria de imagens, convidar um amigo, editar perfil e configurações. Tudo foi feito da maneira mais simples possível buscando facilitar o uso do We Play pelas crianças.

Ao clicar no ícone do Caco, o macaco, no canto inferior direito da tela, o usuário é redirecionado para um tela de configuração do jogo (ver Figura 6d). Nesta tela, ele tem a opção de criar ou procurar uma brincadeira. Na primeira opção (ver Figura 6), o usuário é redirecionado para uma tela de configurações onde ele define suas preferências do jogo. Já na segunda opção (ver Figura 6f), o usuário recebe uma lista de pessoas brincando próximas à ele, e tem a opção de escolher alguma para brincar. 
VI Congresso Brasileiro de Informática na Educação (CBIE 2017)

Anais dos Workshops do VI Congresso Brasileiro de Informática na Educação (WCBIE 2017)

Algumas funções são limitadas pelos pais como, por exemplo, a distância na qual o usuário pode procurar uma brincadeira e se ele pode ou não compartilhar uma brincadeira com outras pessoas. Um trabalho futuro é a implementação da interface da aplicação para os pais também, mas a ideia é que os pais tenham controle de onde e com quem seus filhos estão e que sejam notificados caso algo saia do planejado.

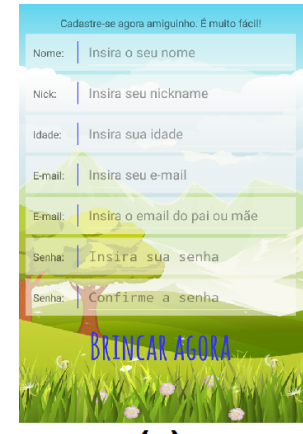

(a)

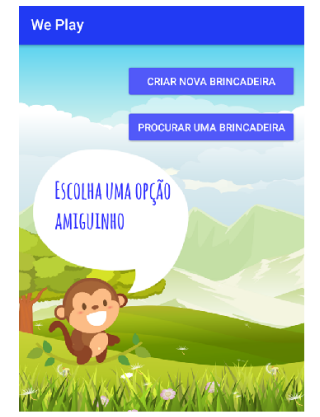

(d)

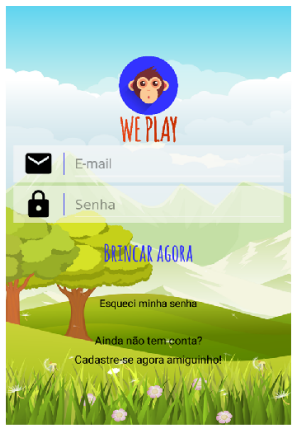

(b)

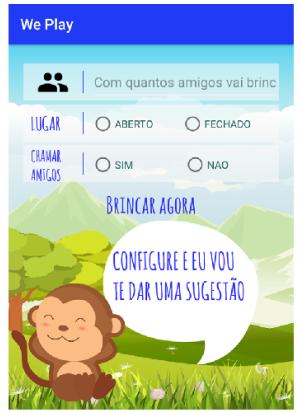

(e)

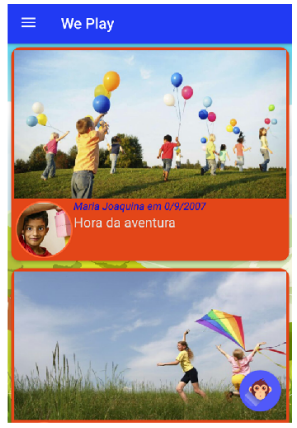

(c)

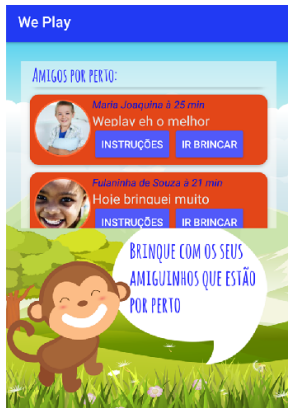

(f)

Figura 6. Telas: (a) cadastro; (b) login; (c) timeline; (d) novo jogo; (e) criar jogo; (f) procurar jogo

De acordo com as configurações realizadas na Figura 6e, Caco, o macaco, irá sugerir alguma brincadeira (explicando quais suas regras e sua forma de jogar - ver Figura 7a) que pode ser aceita ou não pelo usuário. Caso o usuário não aceite, outra sugestão de brincadeira é dada a ele. Caso aceite, ele é redirecionado para uma tela (ver Figura 7b) que tem a possibilidade de gravação de uma selfie ou vídeo da brincadeira para que fique em sua galeria ou na timeline de amigos. Nesta tela também há a opção de começar uma nova brincadeira.

O protótipo clicável do Balsamiq Mockups pode ser acessado em WWW.goo. gl/i2vf7T, o clicável Android pode ser acessado em WWW.goo.gl/ViYeC8 e a apresentação da proposta do We Play pode ser acessado em: wWw.goo.gl/DfaW6t. O vídeo foi produzido utilizando uma versão gratuita do aplicativo PowToon.

\section{Considerações finais}

Este trabalho é importante quando se pensa em ajudar crianças a reduzirem o uso das tecnologias. Como consequência vem os benefícios acarretados a elas, como a ajuda no desenvolvimento e aprendizado, a realização de atividades físicas e a interação social com outras crianças. 
VI Congresso Brasileiro de Informática na Educação (CBIE 2017)

Anais dos Workshops do VI Congresso Brasileiro de Informática na Educação (WCBIE 2017)

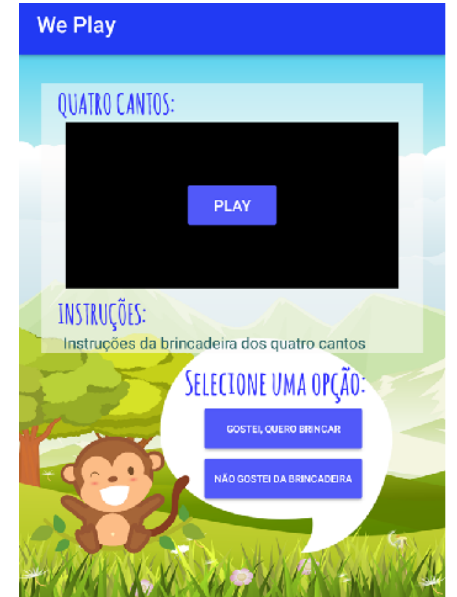

(a)

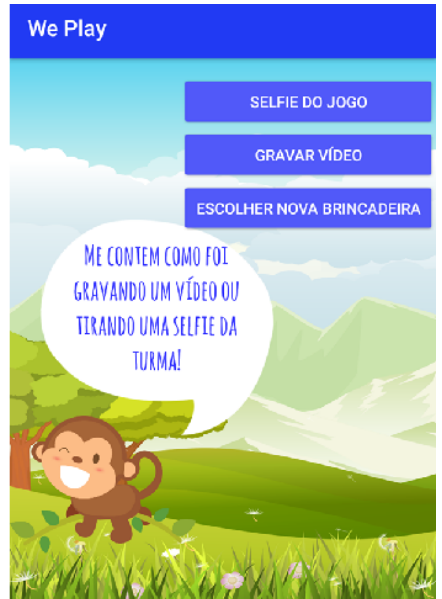

(b)

Figura 7. Telas: (a) sugestão de jogo; (b) fim de jogo

Através dos testes realizados foi possível melhorar a interface do We Play para uma melhor interação com o usuário, confirmar o usuário ideal e receber um feedback positivo das crianças em relação ao uso do aplicativo.

A escolha da plataforma de desenvolvimento do aplicativo foi devido a pesquisa [Brasiliense 2015] realizada pela GlobalWebIndex que mostra um domínio cada vez maior da plataforma Android em cima da $i O S$.

Como trabalho futuro fica o desenvolvimento das telas para controle dos pais, do software propriamente dito do We Play.

\section{Referências}

[Brasiliense 2015] Brasiliense, C. (2015). "estudo mostra crescimento no uso de dispositivos móveis e domínio android". Acessado em 29, Jun de 2017 em http://www.correiobraziliense.com.br/app/noticia/ tecnologia/2015/01/17/interna_tecnologia,466691/.

[Brown et al. 2010] Brown, T. et al. (2010). Design thinking: uma metodologia poderosa para decretar o fim das velhas ideias. Rio de Janeiro: Elsiever.

[Cooper et al. 2007] Cooper, A., Reimann, R., and Cronin, D. (2007). About face 3: the essentials of interaction design. John Wiley \& Sons.

[dos Santos 2000] dos Santos, S. M. P. (2000). Brinquedoteca: sucata vira brinquedo. Grupo A-Artmed.

[Elkonin 1998] Elkonin, D. B. (1998). Psicologia do jogo. Martins Fontes.

[Heller 2013] Heller, E. (2013). A psicologia das cores: como as cores afetam a emoção e a razão. São Paulo: Gustavo Gili.

[Pinto 2003] Pinto, M. R. (2003). Formação e Aprendizagem no espaço Lúdico. Arte \& Ciência. 